\title{
5 New trends in advanced business services
}

\subsection{Global business centres}

The ABS industry is quite a new in the global economy, but it also evolves every day. Someone might argue that the supporting business activities are not very relevant to core businesses. It is a very naïve and superficial view. The value of the office work globally is estimated for more than 10 trillion dollars annually. So introducing any solutions that will bring savings in providing the support functions may be a major innovation. Our focus is more about the quality than quantity of offshoring. We look for the answers to the following questions: What are future areas of development of ABS? How an ABS unit can leverage activities of a MNE? How can an ABS unit contribute to building advantages of the entire organisations?

The growing maturity of offshore ABS units leads to upgrading their operations and improving their position within structures of MNEs. The increasing trend is transforming the operations of a SSC into a global business centre (GBS). The new form of SSC is also referred to as intelligent business solutions (IBS). According to the survey by a consultancy, 61\% per cent of respondents consider their ABS units as GBS (Deloitte, 2017, p. 10). SSON (2019) claims that the landscape for ABS is changing faster than ever before and there are many new developments in the industry. Establishment of a GBS is the answer to profound changes within MNEs. Digitalization helps companies to centralize operations and processes dispersed in many locations (Bhattacharaya, Lang, Reeves, \& Augustrinraj, 2018, p. 10).

GBS can be described using five characteristics (Deloitte, 2013):

- Multi-function

- Multi-region

- Multi-location

- Multi-sourced

- Multi-business.

Some experts envision significant evolution of business services and "the BSCs [business services centres] are entering the next phase BSC 4.0 - the intelligent multimode global super-office.” (ABSL CZ, 2018, p. 9). Companies change names of their service subsidiaries to underline the evolution towards a greater geographic and functional scope of the operations, rising maturity of the processes taking place in the unit, but also its position within the structures of multinational firms. It is the evolution from providing services as somehow an external unit to being a crucial part of the management process. The example of the evolution and naming was an ABS unit of an American oil firm - ExxonMobil in Hungary. On the 15th anniversary of the operations in Budapest the official name ExxonMobil Business Support Center Hungary was changed to ExxonMobil Global Business Center (Gaál, 2019). 
Centralisation increases the application of end-to-end processes within GBS units. Moreover, the process ownership and responsibility of GBS units are rising. The model of consolidated operations proved to be appropriate in many areas. However, it does not end with putting accounting for tens of business units under one roof of GBS. There are still functions that can be more effectively executed in particular locations, than from one central unit.

This relates to processes that are even closer to the core activities of the companies. The list includes logistics, value chain management, production planning, sales planning. In some companies such operations have been already moved to an ABS unit. This may be the remedy for decreasing number of jobs in transactional activities in offshoring locations. Moreover, the activities will be rather of middle or even front office, not the back office. As a default we should assume that many back office jobs are prone to automation, but it may be of limited impact (at least in the coming years) for the middle or front office activities.

The idea of creating a GBS unit is sometimes not an optimal solution. According to Davis (2005) fully centralised global operations are unlikely to replace regional deliveries of business services due to different needs of clients, differences in business environment and legal frameworks between regions and trading blocks. This could be understood as "one size does not fit all". Time zones or legal regulations induce the existence of regional services centres. In general, the operations of foreign firms in ABS in CEE are globally oriented. They aim at standardisation and codification of processes, so they can be delivered to any place in the world. Indeed, rare are cases when services by a centre are provided only to one country. Only $4 \%$ of centres in Poland and 1\% in Warsaw implemented such a model (ABSL, 2018, p. 23). Building a centre to serve only one market is somehow against the main assumption of an ABS unit, that is consolidation of auxiliary services from different countries, in order to improve process execution. Anyway, this can still be important if the consolidation of many units from one country took place in a single service centre. However, this does not have to be the case if we look from the expansion perspective and the service centre was established in order to boost the home country's operations.

We assume that ABS units are created by multinational firms. However, a SSC unit may be also established by a domestic firm with operations in only one country. However, their structure and scope of operations is very different from the global or regional peers. For example, foreign-owned ABS units in Hungary provide services according to three geographic dimensions. First, the largest amount of services is provided for European clients. Such a model is chosen by many global firms, which have vast operations in Europe or even more frequently by large European firms relocating support functions to Hungary. Second option is that services are provided globally and Hungary is the core location for ABS for a multinational. It is also related to the fact that some firms include CEE economies in their global delivery chain. The third option is providing service for businesses in North America. For the largest multinational 
corporations, ABS enable to operate 365 day a year and 24 hours a day. They create a global network of units at different geographical locations and time zones.

There is also evolution of SSC from transactional into knowledge-based activities. It is indicated by names of the units: centre of expertise, centre of competence, or centre of excellence. Indeed, the process excellence is the key element of the strategy of such units. The move towards higher value added activities is the central evolution of SSC. According to SSON (2019, p. 2) "A strong and obvious commitment to Centres of Expertise is a driving force in modern-day Shared Services”.

We focus on GBS as the evolution of captive offshoring, however there are also opinions that the rise of GBS model have been linked with the propensity of firms towards outsourcing. According to Wirtz, Tuzovic, and Ehret (2015) "business service providers can provide solutions reducing a firm's complexity and coordination problems across the supply chain, thus allowing the firm to free resources for new innovations". One of the consultancies in Poland had many processes in their SSC, however they decided to outsource the lower value-added tasks to a large Indian provider with operations in Poland. Thanks to such move the SSC could focus on more value-added and knowledge-intensive activities under the umbrella of GBS.

\subsection{Automation and machine learning in business services}

The notion of AI has usually been associated with driverless cars, autonomous drones, or machines imitating human behaviour. However, from the business perspective more important are less impressive activities that help to reduce costs and errors. Robotic process automation (RPA) or robotic desktop automation (RDA) means executing office tasks by employing bots - computers equipped with software performing business processes without or with just minor human assistance. It is accompanied by the development of new smart software such as BluePrism, Microsoft Cognitive Services, or UiPath. The development of the technology is still in its nascence as the value at the end of 2016 was estimated for $\$ 5$ billion (Willcocks, Lacity, \& Sauer, 2017, p. 6).

A very recent trend in automation of white-collar tasks is intelligent process automation (IPA), which means supporting processes using AI and ML. Automation here means more than just machines using documents or numbers to perform tasks. This is about direct interactions between a human being and a machine. It may take a form of so-called chatbots (officially: intelligent virtual agents, IVAs). Such software can replace a worker in contacts with customers, recruitment process, or technical support. Moreover, a bot can work around the clock with the same efficiency. The automation solutions provide scalability, that means they can serve 10 or 1000 customers per hour. Such flexibility is not possible with human beings.

The idea of employing machines to do things previously executed by human beings is not new. In fact, for hundreds of years it raised the public's anxiety. The introduction of a new technology in textile manufacturing in the 18th century led to 
Luddite riots aimed at destroying the mechanised looms. There has also been a lot discussion about robots in modern industry replacing human hands and performing many tasks faster and with higher precision. This explicitly threatened the employment of blue-collar workers. However, the other side of automation is incorporation of machines mimicking the human brain. This, in turn, can threaten the position of while-collar workers.

What is different when we compare the robotisation in manufacturing with the automation of ABS is that in the latter, barriers are lower and incentives greater. The lower level of barriers means that new solutions are more affordable for businesses, thus the return from the automation is faster. Both lower barriers and higher profits are closely linked to the characteristics of firms implementing the automation solutions in services - large multinational firms. They have incentives to apply advanced solutions, because they can spread them to operations in many divisions and countries. What is important is that such firms have already made an important step toward automation - they already standardised many of their tasks related to office functions.

To clarify notions used in the discussion about automation, it is important to explain the notion of digitalisation first. It means transforming processes conducted in the manual way into binary data. The evolution towards the digitalisation of business services was the first step towards automation. Still just a few years ago, schemes presenting the workflow in services were just emerging. Within a short period of time, precise procedures, that can be executed by machines, have been developed. The necessity to involve human being is decreasing significantly. In just a few years the main role of human beings in ABS will be solving only the most complex tasks.

$\mathrm{AI}$, in early days, was understood as "making a machine behave in ways that would be called intelligent if a human were so behaving" (McCarthy, Minsky, Rochester, \& Shannon, 1955). According to Nilsson (2009) "artificial intelligence is that activity devoted to making machines intelligent, and intelligence is that quality that enables an entity to function appropriately and with foresight in its environment". A narrower understanding and a more humble role of AI was presented by Kaplan and Heanlein (2019), who defined it as "a system's ability to correctly interpret external data, to learn from such data, and to use those learnings to achieve specific goals and tasks through flexible adaptation".

Kaplan and Heanlein (2019) distinguish three systems of AI: analytical AI, human-inspired AI, and humanized AI. Analytical AI is the basic form of intelligence using analysis of past facts to programme future behaviour. Human-inspired AI adds emotions to the cognitive intelligence. This type of AI observes emotions and reacts accordingly. If we add to the cognitive and the emotional intelligence social skills, we obtain the humanized form of AI. In other words, having these three types of intelligence, the machine can imitate the behaviour of a human being.

From the perspective of ABS firms, great gains can be associated with each type of AI, however when we take into consideration the structure of current 
knowledge-intensive business services, the analytical type is particularly worthy of attention. The business functions are associated with analysis of business processes, gathering data, solving current problems and finding solutions aimed at avoiding problems in the future. Moreover, the processes in ABS industry are frequently performed according to the rules imposed externally, like International Financial Reporting Standards (IFRS). It means that processes are typical to many firms and the potential of automation is high. Moreover, the larger the number of companies applying automation, the more widespread and affordable the solutions become. It means that in just a few years most processes related to ABS may be automated. It is confirmed that various forms of automation may replace humans in executing many tasks. Actually it is already happening and many ABS firms have implemented automation solutions. However, from the business perspective it will require significant reengineering of business process. At the moment, thanks to the flexibility of a human brain, even the most complex business problems can be solved. But in order to make application of machines in business services easier, it may be better to adapt processes to the way computers operate than to train computers to solve complex human-oriented processes.

Although the attention is currently focused on the analytical type of AI, there are significant gains from other forms of AI. If emotions are included, such a machine can be a very useful tool of customer service, recruitment or marketing. Such solutions could replace human beings more broadly from the provision of services, even in business-to-customer relations. Social intelligence is not relevant to solving many of business problems, however equipping AI with the social elements would again increase the number of tasks, where AI could be applied. AI may help introducing automation into non-routine tasks and involving high levels of skill (Autor, Levy, \& Murnane, 2003). However, the opinions on AI have not been only positive and optimistic. Acemoglu and Restrepo (2019) concluded that "The considerable promise of AI implies that we need to devote care and serious thought to its implications and to the question of how best to develop this promising technology platform - before it is too late."

The introduction of first computers led to new ideas for AI. As it was earlier mentioned, already in the 1950s there was a promise of building really intelligent machines. However, after several decades there are still no solutions ready to replace human brain in many tasks. Actually, the introduction of computers created many jobs. From the perspective of the ABS subsector, the important jobs such as: record keeping, calculation, or repetitive customer service are those substantially substituted by computers (Autor, Levy, \& Murnane, 2003). So the development of technology modified the jobs, but not replaced them. Naturally it is difficult to compare the events in the technology development, however the end of most jobs should not appear any time soon. Anyway, it does not change the opinion, that there is a revolution expected in job markets and jobs' content.

Automation of ABS is considered by companies as the core disruption in recent years. However, the bold declarations have not materialised yet. According to Deloitte 
(2017, p. 16) 42 percent of ABS firms have not started any robotic process automation (RPA) preparations and only 4 percent automated multiple processes. Anyway, automation is gathering pace, and new solutions emerge constantly.

The process of automation has started some time ago at leading companies. Observing the path we can distinguish four steps (Figure 6). First, managers in organisations start treating services as processes that can be divided into smaller tasks and instructions of delivering them should be prepared. As a result, the knowledge that was once of a tacit nature becomes codified. When the first step is completed and there is enough information about services provided in various units of an organisation, it is possible to standardise many of them and implement common solutions. In the third stage, it is possible to consolidate tasks in one or few units. This is the phase when a shared service centre may be created or the activities may be outsourced to an external service provider. Consolidation also requires achieving a certain scale of activities, because only then it is justified to arrange their execution within new structures. When the processes are standardised, consolidated and streamlined, there is room for applying automation.

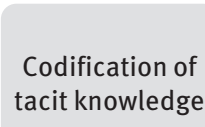

tacit knowledge

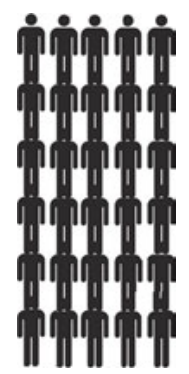

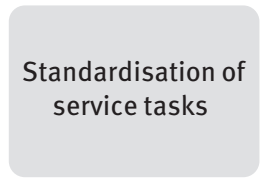

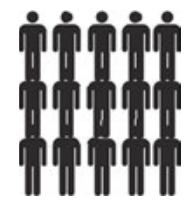

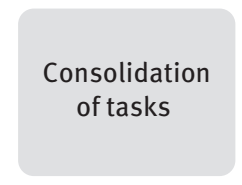

iminini
Automation of tasks

Figure 6: Process of transformation of headquarters' services and headcount (source: own elaboration).

The change in headcount can be best illustrated by a case of an ABS unit, which used to hire 20 financial specialists. Once the process was automated, there were still 15 positions, but 7 of them were taken by bots, 2 bot trainers and 6 financial specialists solving the most complex and non-repetitive cases. And this is not the end of the evolution, so the number of human beings in the process is still expected to fall. 
Actually, when all new processes are taken into consideration, the hybrid approach to ABS units will be the most appropriate. It means that many processes will be conducted by bots supported by humans. Moreover, there are no arguments yet that the highly demanding mental processes will be soon performed by machines. An important view on $\mathrm{AI}$ is the cooperation with human beings. Machines and people are complementary in the "organizational decision-making processes typically characterized by uncertainty, complexity, and equivocality” (Jarrahi, 2018). Thus, for managers of ABS firms it is important to understand that machines should augment human beings, not to replace them.

Nowadays, the main focus of researchers is the displacement effects of labour caused by automation. The evidence confirms that labour's share in the value added has been recently reduced (Autor \& Salomons, 2018). They conclude that recently the automation is not aimed at labour-augmenting but rather at labourdisplacing. In other words, there are no gains in the labour's productivity, but there is a trend towards replacing it with cheaper machines (Zeira, 1998; Autor, Levy, \& Murnane, 2003). The interest in AI is rather from manufacturing perspective, sometimes from the customer services, but not much from business services.

The biggest impact of automation is for middle-level occupations. The literature on automation underlines the notion of tasks in understanding presented by Grossman and Rossi-Hansberg (2008). This is because automating a task does not mean automating an occupation (Bessen, 2016). Tasks requiring high skills are not possible to automate due to their cognitive nature, whilst those of low-level are also not possible to automate due to detailed manual handling (Mandelman, 2017). Moreover, the introduction of various information technologies had positive impact on autonomy of workers and widening the span of control (Bloom, Garicano, Sadun, \& Van Reenen, 2014). This may lead to making firms flatter and elimination (not only reduction) of middle-skilled jobs.

According to McKinsey Global Institute (2017) "while few occupations are fully automatable, 60 per cent of all occupations have at least 30 per cent technically automatable activities". Their approach is that many occupations are quite resistant to automation, however thanks to automation of some tasks, the productivity may rise.

Studies confirm that office and administrative jobs are in the same category of jobs highly threatened by automation as production occupations (Frey \& Osborne, 2017). As a social consequence, the automation is expected to decline the number of routine-based jobs, erode wages of medium-skilled workers, and benefit those in non-routine occupations (Wright \& Schultz, 2018). According to a consultancy "more than 1 million jobs are at risk in four countries alone: the United States, Poland, India, and the Philippines" (A.T. Kearney, 2017). Interestingly, according to World Economic Forum (2018), the jobs that are on decline are expected to fall of 18 percentage points already in 2022 in comparison to year 2018. The titles in the declining category include among other: accounting, bookkeeping and payroll clerks, data entry clerks, telemarketers, client service and customer workers. Importantly, those are the 
jobs, which create the bulk of operations within white-collar services in CEE. The jobs on the rise are: digital transformation specialist, data analysts and scientists, process automation specialist.

There are several completely unexplored areas related to automation of business services. First, it is necessary to introduce an international setting for the automation, with particular attention on offshoring. Offshorability (the possibility of conducting processes in offshore location) of jobs does not equal automation of jobs (Frey \& Osborne, 2017). Cashiers have been replaced by automation teller machines, however the activity must be performed at a specific place. Anyway, there is direct link between routineness and offshoring (Goos, Manning, \& Salomons, 2014). It would mean that routine tasks were once moved from advanced economies to low-cost locations, but now the tasks will be transferred to bots. It means there will be no direct increase in the number of jobs in advanced economies due to the downfall in the offshoring. Only limited number of jobs may be created to support bots. The issue is how to attract the remaining jobs and where to locate bots.

Offshoring of tasks, when measured on the sample of American firms, led to the larger size and higher productivity by firms offshoring some tasks (Monarch, Park, \& Sivadasan, 2013). However, according to their evidence such firms suffered a large decline in employment and output relative to their peers. It means that jobs were partially moved abroad. If we employ automation in host countries, it means that the jobs may be replaced by machines.

The other neglected element of the analysis are also changes in firms due to automation. According to Aghion, Jones, \& Jones (2017), the internal organisation of firms may evolve due to introducing AI. They based such an opinion on an earlier analysis of UK firms and proposed a simple of model of a firm with "high-skilled" and "low-skilled" occupations (Aghion, Bergeaud, Blundell, \& Griffith, 2017). They focused on the position of particular occupations, even analysed outsourcing, but they did not include offshoring in their framework.

An important element that cannot be overlooked is the dominance and concentration of market power by a relatively limited number of firms. They are also called superstar firms (Autor, Dorn, Katz, Patterson, \& Van Reenen, 2017). According to their results, the growing dominance of such firms leads to the decline of labour share in value-added and sales of firms. The notion of superstar firms can be stretched to multinational enterprises. They are predominantly capable of introducing advanced technologies like AI. MNEs also dominate when it comes to offshoring of white-collar jobs.

\subsection{Transformation of business services and their execution}

The impacts of the transformations in the ABS industry can be observed in the job market, financial performance of firms, global organisation of firms, and flows of 
FDI. The issue that was also raised is whether MNEs will conduct more service operations in a home economy or maybe abroad. One of the threats for the industry of services offshoring is its expected decline. There are arguments against further development of captive offshoring as well as against outsourcing abroad. Sometimes the expectations are that the growth of one type will be at the expense of the other. Captive activities are supposed to be limited due to the automation and the rise of specialised providers. Technology is at the same time expected to limit scope of outsourcing as well as platforms offering freelance service providers instead of institutionalised providers.

However, there is still plenty of room in the market to grow. Still around $60 \%$ of IT activities and around $80 \%$ of office tasks are executed in-house (Willcocks, Lacity, \& Sauer, 2017, p. 19). Thus it is considered that they can be outsourced. However, it is not always an option as companies tend to keep a certain level of control over data and processes. The statement about the large portion of processes still inside an organisation may mean that companies opt for captive offshoring. Actually, the vast study of literature and business cases does not give an unequivocal answer to the idiosyncratic decision between captive and outsourced business services mode.

According to Avendus, a consultancy, the analysis of global market for ABS can be divided into two main types of activities: business process management (BPM) and information technology (IT) services. The notion of BPM comprises activities considered as SSC and BPO in this book. The current state of offshoring and its further potential of growth can be seen by the comparison of values of global sourcing and global usage of particular services (Figure 7). Value of global IT services is more than three times larger than BPM, however IT services are still to a limited extend globally sourced. Only around $15 \%$ of global sourcing means that there is still a significant potential for further development. The BPM sourcing may in turn seem more saturated with more than a third already provided from abroad. However, as more and more processes have been streamlined and tasks commoditised it is expected that the share of international sourcing will continue its growth.

ITO services have been disrupted by the cloud computing and a new type of activities emerged - cloud sourcing. It is directly connected to delivering ITO services, however it impacts various types of operations of enterprises. Thanks to cloud sourcing the other, technological innovations can be included in the delivery package of services, like big data analytics or automation.

Transformations of ABS are linked to changing working conditions. According to some statements, workers of the futures will be part time independent contractors with high qualifications. Anyway, it is pretty simplistic to think that flexible work arrangements in the form of "crowdsourcing, contract work, part time work and job sharing will promote the inflow of new creative minds and well educated workforce into BSCs” (ABSL CZ, 2018, p. 7). I argue that highly qualified and scarce employees cannot be treated just as an input. The economy of sharing jobs (also known as a gig economy) is frequently associated with companies treated their 


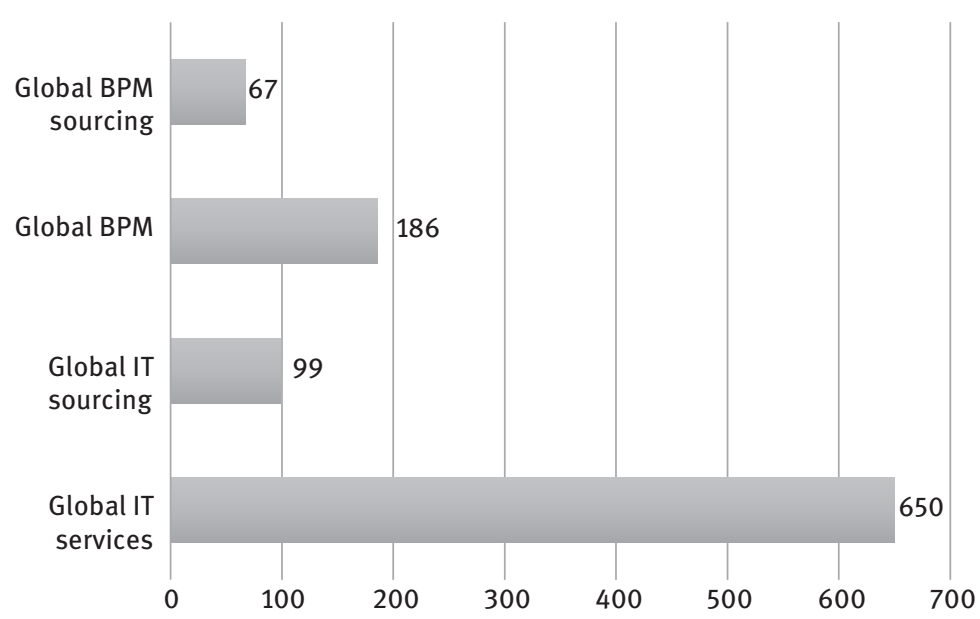

Figure 7: Global advanced business services market (2016, in billion USD) (source: own elaboration based on Avendus, 2017).

workers like contractors in order not be liable for their social contribution. Opinions from the United States, where the gig economy is already advanced, that it is a way of exploiting workers using modern technology (New York Times, 2017).

When we link the gig economy to automation in ABS units, there is a large mismatch between creativity and exploitation. BCG in their report claims that gig work is good both for companies and workers, however they conclude that "freelancers aren't the only option for companies looking to source critical talent in a flexible way" (Wallenstein, de Chalendar, Reeves, \& Baily, 2019). There are more arguments against possibility of using freelancers as a source of long-term competitive advantage. The example of the ridesharing company Uber reveals that only $4 \%$ of its drivers are providing their services for longer than one year (McGee, 2017). In the knowledge-intensive activities such a high rate of turnover would make it impossible to train workers. There is also an issue of accessing sensitive corporate and personal information by short-term contractors.

The issue are also employment relations, increased job insecurity and risk of marginalisation of certain categories of workers (Drahokoupil \& Fabo, 2019). The answer to the problems with weakening linkages between employers and employees in the service sector may be creating work ecosystems, which will govern this special relationship (Subramony, et al., 2018). However, there are the same concerns raised about access to data assessment, or retention.

The offshoring and outsourcing of services are currently in the phase of significant commoditisation. It means that there are exact procedures and instructions helping to execute the transaction in a repetitive manner. The highlighted result of the commoditisation is automation and employing specialised software executing 
ABS. However, a less pronounced development in the delivery of services is the rise of micro providers and platforms allowing them to offer their services as a part of a global value chain. It gives the individuals possibility to serve as contractors to BPO or captive offshoring units and to work in locations, where such service units are not present (Lehdonvirta, Kässi, Hjorth, Barnard, \& Graham, 2019). It may be an opportunity, but also a threat to established providers of services. On the one hand, it will help with the shortage of skilled labour in main service clusters. It will also eventually unbundle the services from the geographical locations. It is important as services are already frequently transmitted electronically, however the clustering becomes even more important. As a result the basic characteristics of ABS will be fully utilised. It also means that the talent pool will be greater and accessible from very distant locations.

However, there are also threats to the established organisations. The competition from micro providers may squeeze margins as new large group of vendors enters the global market. Anyway, many processes cannot be transferred to those providers due to the complexity, necessity of interactions with stakeholders or the secrecy and data protection.

\subsection{Cybersecurity and data protection}

The most important characteristics of advanced business services is dealing with processes based on data. The greater scope of operations in an ABS unit the more data, also of the sensitive nature are collected, transformed, and exchanged with other units within the enterprise, but also with external partners. Such activities are subject to rising regulations and risks. Various economies introduced specific laws regarding data storing, protection and transfer. One of the most important is General Data Protection Regulation (GDPR) introduced by the EU. The issue of offshoring is important in this context as it introduces the transfer of data across borders. It means that companies organising a global or regional centre need to take into consideration the restrictions to the flow of data. The issue is that in many cases it has not been regulated yet, so it induces firms to introduce internal regulations.

The limitations of data transfer may be also a business opportunity for companies working within the same legal framework. For example, EU firms may be willing to choose one of EU economies to work with data, as the regulations are common. There is also an issue of data localisation. It means that they should be stored and processed within the border of a country. The case may be Russia with its regulations regarding localisation of all personal data or China requiring the same for personal, as well as business and financial data.

The issue is also transferring important data to economies, which have not been considered as role models with respect to data protection. In such a case the providers from those economies must prove that they are able to operate using the best 
international practices. However, the issue is that there is a limited guarantee that the local authorities will not access the data of foreign companies. Unfortunately, companies transferring their data have not been concerned much about the issue and sometimes recklessly focus only on the costs of operations.

There is also an issue of cybersecurity. A cyberattack may endanger the existence of the entire organisation due to a breach of data. The fact that companies possess large amount of data means the value of them is rising significantly. It is exacerbated by offshoring, as the centralised units managing data may be targets of such attacks. Therefore a very important issue is data management in the offshore outsourcing and captive offshoring arrangements.

It is stressed that the security issues related to data are multifaceted and require treating many aspects as interrelated. According to Nassimbeni, Sartor and Dus (2012) there are three main dimensions of the security issues related to outsourcing and offshoring of ABS:

- Organisation dimension - related to efforts of an enterprise to implement policies and procedures on data security,

- Legal dimension - related to the legal environment for the enforcement of the cooperation between an enterprise and its data operators,

- Technical dimension - related to the ability of introducing technical solutions aimed at increasing the security of data.

Problems later resulting in the security issues regarding offshoring and outsourcing can relate to the following activities (Nassimbeni, Sartor, \& Dus, 2012):

- Activity selection,

- Entry mode choice,

- Location choice,

- Supplier selection,

- Contract drafting,

- Management of the transition,

- On-going project.

The list includes activities prior to the foreign assignment of tasks, change management and execution of the project. From the managerial perspective, it requires a holistic approach to planning the offshoring process, and the security issues should be a central point in the decision-making. It is also important to state that the security issues require to treat offshoring not as a low-cost solution, but rather a complex and strategic objective of an enterprise. It means that the appropriate amount of human and financial resources should be devoted to the organisation of the transaction, which should accompanied by a regular oversight by the top management of an enterprise. Failures in the aspect may have damaging consequences for the company. 
There have been many cases of security issues related to data when it comes to the outsourcing. Probably the most striking was the case of the American National Security Agency, which was affected by the leak of information by a contractor in 2013. There have been many other cases of cyberattacks, not directly related to offshoring or outsourcing, however they were also results of the exchange of data between firms.

The security issue is also the reason why some companies are reluctant towards offshoring and especially outsourcing of the valuable content. The banking or insurance sector as those employing rather captive offshoring, not offshore outsourcing due to regulations. It does not only involve dealing with the financial data of their clients, but it is also related to internal processes, like HR management.

The four main trends presented in this chapter refer to distinctive elements of the ABS execution. However, they should be perceived as a total unity due to the fact that they are interdependent and aim at increasing the efficiency of provision of knowledge-intensive services. They all have a grave impact on the young ABS industry and its transformation should be perceived as a new normal. 